\title{
Flexible labor regimes, new technologies and women's labor: case studies of two electronics firms in Malaysia
}

\begin{abstract}
In today's situation of Malaysia's industrialization, the issue of cultural and social stigmatization of women workers is no longer relevant. The empirical picture shows that, with increasing automation, greater concern about appropriate human resource management strategies has become usual in dealing with labor. This study indicates that in the capitalintensive electronics industry, management have been quite successful in eliciting their workers' cooperation in keeping in step with the new technology introduced. This article looks at the evidence of changing technology at die workplace and documents management strategies that are currently being employed to either áontrol,ôćontain,ôámpowerôor óselfenhanceôlabor. It concludes that the proliferation of new skills has created new management strategies that can empower women workers, but only if they can also have autonomy in gaining knowledge of the new technologies that they encounter on the shop floor.
\end{abstract}

Keyword: Women workers; Technology; Skills 